\title{
THE CHALLENGES HINDERING THE IMPLEMENTATION OF ENVIRONMENTAL MANAGEMENT PRACTICES IN HOSPITALS
}

\author{
MAY A. MASSOUD ${ }^{1}$, FATME NASSERDDINE ${ }^{1}$, NASSER YASSIN ${ }^{2}$ \& RIMA NAKKASH ${ }^{3}$ \\ ${ }^{1}$ Department of Environmental Health, American University of Beirut, Lebanon \\ ${ }^{2}$ Department of Health Management and Policy, American University of Beirut, Lebanon \\ ${ }^{3}$ Department of Health Promotion and Community Health, American University of Beirut, Lebanon
}

\begin{abstract}
Healthcare services aim to reduce health problems and to prevent potential health risks. However, in doing so, waste is often generated that can adversely affect public health and the environment. This environmental impact is often neglected or overlooked, possibly due to the fact that non-clinical programs are generally not funded, and pollution prevention programs require a shift in thinking. Moreover, environmental management practices are mostly not compliance-driven. This research aims to: assess the perception of concerned stakeholders in hospitals in Lebanon, with regards to environmental standards and the impacts of their activities on the environment; investigate the challenges of implementing environmental management practices; and identify possible enhancing factors. Accordingly, in-depth interviews were conducted with concerned stakeholders from hospitals with different sizes. Thematic analysis was employed to thoroughly examine and evaluate the transcripts comprehensively, following the set objectives of the research. Findings revealed that the main challenges hindering the implementation of environmental management practices in hospitals are primarily employee resistance, lack of financial resources and qualified personnel, lack of awareness, lack of treatment methods and lack of support from the government. The enhancing factors that were recommended by the stakeholders revolve around financial support, training programs, rewards systems and improvement of standards. Developing sustainable environmental management practices requires a change in staff behaviour, which often occurs through ongoing staff education and training. Strengthening human and institutional capacity through a combination of training, technical assistance, and awareness programs is an essential initial step toward realizing effective environmental management practices.
\end{abstract}

Keywords: environmental management practices, challenges, enhancing factors, Lebanon.

\section{INTRODUCTION}

Paradoxically, healthcare facilities primarily hospitals pose a potentially significant threat to the environment and consequently to public health as they fulfil their responsibility towards patients' care. Hospital processes consume large amounts of water and energy and hence contribute to resources depletion. Moreover, they contribute to environmental pollution owing to the production of hazardous and non-hazardous waste, emissions of air pollutants and generation of wastewater. Hazardous waste may include pathogenic and infectious material, chemicals, pharmaceuticals, sharp and radioactive items, and waste with heavy metals content. Although a very small percentage (10-25\%) of the total healthcare waste is considered hazardous, it still poses a significant adverse effect to both human health and the environment due to their characteristics. If not managed (stored, treated and/or disposed) properly, medical waste poses a risk onto the environment.

Hospital processes in the various departments such as medicine, surgery, operating rooms, delivery, coronary care unit, and intensive care units generate wastes which are usually contaminated with patient body fluids or may also contain human organs from surgeries. Of particular concern is the chemo-waste generated in the chemo-department and oncology. The lack of environmental management practices in hospitals negatively 
influences staff, patients and population's safety leading to additional costs, overuse of natural resources and pollution. Accordingly, it is imperative to enhance environmental management practices in the healthcare sector with a holistic approach which can go hand in hand with the improvement of quality of services as well as staff and patients' health protection.

Environmental degradation is among the factors influencing human health; thus, contributing to an increase in diseases due to exposure to various biological, physical and chemical agents. As such, hospitals should adopt preventive healthcare approaches and leap forward in environmental protection. Many international and national agencies worldwide have established numerous approaches to mitigate and control environmental impacts as well as enhance environmental management practices of the healthcare facilities without cutting on patients' safety and comfort. Several hospitals are adopting formal environmental management systems and are sharing their best practices. The accreditation system is one of the indirect solutions to reducing and controlling the negative environmental impacts during the delivery of healthcare services. The accreditation process requires that the accrediting body recognizes that a healthcare organization is complying with standards including environmental aspects. Further on, within the hospital setting a multidisciplinary team should be responsible to improve environmental management practices and performance [1].

Developed countries have been generally successful in implementing hospital accreditation for several reasons. Becoming an accredited hospital may call upon renovating the facility, changing procedures, intensively training employees, and purchasing expensive equipment and instruments to comply with standards. Furthermore, the audits and inspections are additional financial burden to most hospitals as they require fees to arrange meetings and inspections. Governments in developed countries have addressed this critical issue by providing financial incentives to encourage hospitals to apply for accreditation [2]. On the other hand, developing countries are less advanced in this field particularly with regards to environmental standards required for accreditation, but are starting to show gradual development. A number of studies have been conducted in relation to the healthcare waste management that reported the various challenges developing countries face including but are not limited to the lack of data on waste generation, the gaps in the management framework such as the absence of suitable treatment and disposal options, minimal enforcement of legislations and laws and lack of financial and human resources [3], [4].

Lebanon witnessed a shift in the quality of healthcare since the year 2000 whereby it changed from the traditional objectives of physical structure to the multidimensional view focusing on managerial performance. To a certain extent, environmental control was included as part of the multidimensional focus. In Lebanon accreditation is not mandatory by law; however, any hospital contracted with the Ministry of Public Health (MoPH) should be accredited. Moreover, the accreditation system does not mandate all standards for implementation. As such, it focuses on certain standards and neglects others such as the environmental standards [5]. The accreditation program includes 42 chapters of which two chapters are concerned with the management of environmental impacts (Chapter 16 Environmental Services, and Chapter 42 - Waste Management). Chapter 16 includes 15 clauses related to the existence of a competent manager for the environmental service department, orientation manual, comprehensive policy for various areas such as the operating room, quality improvement plan, and the presence of an educational program. Chapter 42 encompasses 8 clauses that cover the presence of a coordinator for waste management department, policies and procedures related to waste segregation and 
handling, appropriate method of disposal of clinical waste and the existence of an occupational health and safety manual. Unfortunately, none of these clauses are mandatory which implies that hospitals are not required to implement any of the standards related to the management of the environmental impacts.

Environmental protection is a legal obligation for hospitals in Lebanon, particularly with regards to healthcare waste management. In view of the weak regulatory enforcement, the accreditation should be used as a mean of advancing environmental issues. Moreover, healthcare facilities should accept their environmental responsibilities to reduce the adverse impacts of their operations. This research project aims to assess the perception of concerned stakeholders in hospitals with regards to environmental standards and the impacts of their activities on the environment, investigate the challenges of implementing environmental management practices and identify possible enhancing factors.

\section{RESEARCH METHODOLOGY}

\subsection{Study design}

Qualitative method, specifically in-depth interviews were adopted as this allows the collection of a great deal of detailed information within a short period of time. In-depth interviews are usually less structured and depend on open ended questions that guide the respondents through. This approach gave all stakeholders the chance to thoroughly explain their experiences and opinions towards the implementation of environmental standards.

\subsection{Recruitment of hospitals}

The purposive sampling which is based on setting selection criteria for participants was followed [6]. It allowed the researcher to group all possible hospitals and select 18 hospitals (Table 1) to take part in the project based on the following criteria:

- Hospitals that are accredited by the Lebanese MoPH.

- Representative of the 6 Mohafazas/districts in Lebanon.

- Private- and public-sector representation of the hospitals.

- Size: the number of beds and capacity of a hospital.

The dates of the hospital's establishments varied from 1902 to 2014 the most recently established hospital. The total number of employees varied between 50 and 1400 employees. The year of receiving the first accreditation also varied between the year 2000 and the year 2012. The 18 hospitals were contacted by phone so as to introduce the research to the Directors or General Managers and get their approval in including them in the research study and to identify the person that should be interviewed from their part. The nominated interviewees of the hospitals were contacted by phone to set up a face to face meeting at their institutions. Stakeholders were also provided with a copy of the interview guide prior to the interview. Often the person that is responsible for the environmental issues is the same as the one for health and safety, logistics, maintenance or engineering.

\subsection{Data collection}

An interview guide was formulated including both general and specific questions. This interview guide helped focusing the interview without locking it into a fixed set of questions in a rigid order and with specific wording. Table 2 summarizes the in-depth 
questions of the interview guide related to the study's objectives. The interview was 25-30 minutes long and was carried out in the language that is most suitable for the respondent (Arabic or English). Leading questions that might have influenced respondents' answers were carefully avoided. Note taking was used to be able to document the whole interview process since some of the respondents did not approve to be audio-taped.

Table 1: Hospitals that participated in the study and their distribution based on Mohafazas, sector and size.

\begin{tabular}{l|l|c|c|c|c|c|c|c}
\hline \multirow{2}{*}{ Sector } & Size & Beirut & $\begin{array}{l}\text { North } \\
\text { Lebanon }\end{array}$ & $\begin{array}{l}\text { South } \\
\text { Lebanon }\end{array}$ & $\begin{array}{l}\text { Mount } \\
\text { Lebanon }\end{array}$ & Bekaa & Nabatieh & Total \\
\hline \multirow{2}{*}{ Public } & Large $^{*}$ & 1 & - & 1 & - & 1 & 1 & 4 \\
\cline { 2 - 10 } & Small & - & 1 & - & 1 & - & - & 2 \\
\hline \multirow{2}{*}{ Private } & Large & 1 & 1 & 1 & 1 & 1 & 1 & 6 \\
\cline { 2 - 10 } & Small & 1 & 1 & 1 & 1 & 1 & 1 & 6 \\
\hline \multicolumn{2}{l}{ Total } & 3 & 3 & 3 & 3 & 3 & 3 & 18 \\
\hline
\end{tabular}

*Small: Number of beds less than or equal to $100 ;{ }^{* *}$ Large: Number of beds more than 100 [7].

Table 2: Summary of the questions that were addressed linked to the study objectives.

\begin{tabular}{l|l}
\hline \multicolumn{1}{c|}{ Objectives } & \multicolumn{1}{c}{ Questions } \\
\hline $\begin{array}{l}\text { Asses the perception of employees } \\
\text { working in hospitals with regards to } \\
\text { environmental standards and the impacts } \\
\text { of their activities on the environment. }\end{array}$ & $\begin{array}{l}\text { 1. What is your opinion on environmental } \\
\text { policies/standards in the accreditation } \\
\text { program? } \\
\text { 2. What are the impacts that your hospital has } \\
\text { on the environment? } \\
\text { 3. In your opinion, are these impacts significant } \\
\text { and important to mitigate and prevent? }\end{array}$ \\
\hline $\begin{array}{l}\text { Investigate the challenges of } \\
\text { implementing environmental } \\
\text { management practices. }\end{array}$ & $\begin{array}{l}\text { 4. How do you address the following } \\
\text { environmental standards in the accreditation } \\
\text { manual: Wastewater, Hazardous waste, Air } \\
\text { emissions? }\end{array}$ \\
\hline $\begin{array}{l}\text { 5. What are the challenges faced when } \\
\text { implementing environmental management } \\
\text { practices? }\end{array}$ \\
$\begin{array}{l}\text { Identify possible enhancing factors to } \\
\text { implementing environmental } \\
\text { management practices. }\end{array}$ & $\begin{array}{l}\text { What are the incentives that would encourage } \\
\text { you to implement environmental } \\
\text { management practices? }\end{array}$ \\
$\begin{array}{l}\text { 7. Do you think receiving an environmental } \\
\text { certificate, such as ISO 14001, in addition to } \\
\text { accreditation is an incentive? }\end{array}$ \\
\hline
\end{tabular}


The information that the hospital representatives provided was treated confidentially and the hospital name was not displayed in the report. Before carrying out the interview, consent was taken from the interviewee. They were informed that the name and data collected from the hospital will remain anonymous, and that all confidential and specific information gathered will only serve the analytical purposes of this paper. Individual responses are not linked to individual hospitals or respondents.

\subsection{Data analysis}

After the necessary data was collected, the content analysis technique was used to analyze the information. It required classifying, summarizing, and tabulating all data. The basic process of analyzing the data is by recognizing differences and similarities between all interviews. Categorizing the data was done by extracting common themes from all interviews and tabulating them to better understand the challenges and experiences of the selected hospitals regarding environmental management practices. Qualitative data analysis was approached systematically to prevent outcomes subjectivity. Results and discussions of each theme were reported. Also, trends and patterns that reappeared among different interviews were identified. Furthermore, direct quotes from participants were used to support common themes.

\section{RESULTS AND DISCUSSION}

\subsection{Perception of environmental impacts and standards}

The majority of the stakeholders in the various districts perceive the production of hazardous waste as an environmental impact. However, the significance of the impact varied as some believe this impact to be highly significant and others believe it is minimal. The fact that the wastes generated in certain hospitals are managed by a private company lead to the perception that the impact of generating hazardous waste on the environment is minimal. Research shows that hazardous waste from hospitals poses a significant impact on the environment. However, studies also show that most of hospital employees are unaware of the severity of the situation. This necessitates awareness raising and education on environmental issues and particularly management practices.

Some stakeholders, mostly from hospitals located in Beirut and Mount Lebanon, believe that their hospitals might cause water pollution as they are discharging the contaminated wastewater within the municipal sewer system. This may be attributed to the fact that hospitals are not connected to on-site wastewater treatment plants for pre-treatment before discharging contaminated water into the municipal network system. Respondents who think that they are not contributing to water pollution explained that water contaminated by infectious diseases through urine and blood is being disinfected with hospital approved disinfectant and diluted prior to discharge. This corrective action is insufficient and reflects the lack of knowledge and comprehension regarding environmental issues. While the majority of stakeholders consider that their activities do not have any impact on air quality, few responded that they may be causing air pollution as a result of the electricity generators. Yet, they perceive this impact as being non-significant. A number of stakeholders belonging to small hospitals reported that they do not contribute to any adverse environmental impacts while performing their services. One of them noted:

"We are a small hospital so there are no environmental impacts that we are causing. Besides, all hospitals have environmental impacts. It is not only us." 
Another respondent explained that:

"We are not polluting the water because we are a small hospital and don't

have a lot of workload. All in all, we do not have any environmental impact."

The fact that some stakeholders in hospitals have limited knowledge and training in environmental issues may affect their attitude towards environmental impacts of their activities and environmental management practices. When asked about the environmental standards that are part of the accreditation program, the majority of the stakeholders consider them not applicable as implementation is often difficult and challenging. Moreover, most of the stakeholders consider the environmental standards as being unclear and difficult to understand and implement. The standards are too general and vague and do not specify the objective of each criterion. Stakeholders also explained that the language of the standards is difficult to understand and that they prefer a new clearly worded standard be established. El Jardali et al. [8] presents similar results in his study that assesses the challenges of implementing accreditation standards in general whereby many of the employees find it difficult to implement the standards because the concept of accreditation is new and unclear.

Another issue that was reported by most of the stakeholders is the lack of treatment methods within the environmental standards that should address specific environmental problems. For example, the Waste Management Chapter does not address the treatment of chemo and cytotoxic waste as well as expired drugs. Several stakeholders believe that the environmental standards require further improvement. When asked to explain why, one of the stakeholders in a small hospital in South Lebanon responded that:

"There exists a lot of useless documentation. Standards should concentrate on managing environmental issues instead of concentrating on managerial issues."

Some stakeholders believe that the environmental standards are not enforceable in a developing country like Lebanon. They further elaborated that there is no continuous inspections and audits being conducted by the National Accreditation Committee and/or the $\mathrm{MoPH}$. According to the World Health Organization (WHO), strengthening legal support is crucial for the effectiveness of an accreditation program. Laws and regulations should be set and enforced to support the accreditation program [2]. Moreover, not implementing the environmental standards may be linked to the lack of a penalizing system which does not fine hospitals that fail to implement them or ensure proper environmental management practices. Furthermore, the lack of enforcement is sometimes a result of the overlap in responsibility by different ministries. Few participants consider the environmental standards basic and fair. Given that Lebanon is an insecure country as a result of political instability together with the medium to low-income status, having flexibility in implementing the environmental standards is contemplated acceptable.

\subsection{Challenges of implementing environmental management practices}

While very few stakeholders reported that they did not face any difficulties when partially implementing the environmental standards, the majority, irrespective of the district, size, and sector of the hospital, responded that implementing the standards is a financial burden. Due to limited financial resources, it may be difficult to hire qualified employees, purchase new equipment to enhance the implementation of the standards, or even afford the cost of surveys. The infrastructure of many hospitals hinders the implementation of the environmental standards. For example, some hospitals are constructed in a manner that does not respect the positive flow of the waste collection traffic; thus, increasing the possibility of infection transmission. A research study conducted by Saleh et al. [7] that 
explores the views of stakeholders in Lebanese hospitals on the expenses of accreditation revealed that about $77 \%$ consider infrastructure maintenance a burden. Hospitals in developing countries may be disadvantaged because compliance may require massive investments beyond available resources and capabilities. The issue of wastewater management is similar to that of the solid waste aspect as all hospitals lack an efficient onsite wastewater treatment plant. Hospitals discharge considerable amounts of chemicals and microbial agents in their wastewaters. Considering that sewer lines within hospitals are connected to the municipal wastewater network and the fact that most areas in Lebanon lack effective wastewater treatment plants, may lead to greater threat than the original diseases.

Many stakeholders in private and public hospitals regardless of size consider employee's mentality and resistance a major hurdle in implementing the environmental standards. They elaborated that training staff causes stress because of their mentalities and convincing them to perform differently is very challenging. Studies show that employee resistance is more common among medium to large hospitals as they usually consist of a larger group with heterogeneous mentalities, in addition to the hierarchically organized staff which contribute to deterring the implementation of standards. Smaller hospitals are often based on a more homogeneous culture and mindsets [9]. Resistance to behavioral change and attitudes of employees at the hospital level are among the most common causes of failure to comply with standards [2]. Some of the reasons behind employee resistance may be age and anxiety. Older individuals may likely show more resistance to change as it is more challenging to convince them to change their behavior. Similarly, anxiety resulting from the increased overload and the possibility of failure may also result in employee resistance.

The lack of qualified and competent personnel responsible for implementing the environmental standards is another major challenge that was reported by most stakeholders. Some of the respondents explained that if they have more qualified employees then the implementation would be enhanced and effectual. Some of the participants reported that the lack of treatment and management methods is an additional barrier that hinders the implementation of the standards. For example, the lack of management of chemo waste, cytotoxic waste, and expired drugs leaves a lot of employees clueless as to how to manage and deal with these wastes. The environmental chapters in relation to accreditation do not address treatment methods or alternative services to treat these types of hazardous wastes. A number of stakeholders think the lack of support by the concerned ministries is an impediment towards implementation of the environmental standards. One of the stakeholders in a public hospital in Beirut district explained that:

"We need the government to support us with detailed standards. A consultant that is ready to train us and advise us when needed should always be available. We simply want a specialized/expert people as a reference to guide and train all hospitals on the same approach."

A study conducted by Novaes and Neuhauser [10] underscored the support of the ministries of public health to hospitals. The study reported that support can take place by first establishing a task-oriented multidisciplinary team in order to review existing standards and develop new standards that are more applicable to all hospitals. It emphasized the need to fund hospitals in order to implement environmental standards with the support of other agencies. Others added that policies and standards should complete each other because they both have common goals and should work in parallel. Generally, the lack of appropriate infrastructure, unsound policies, and ineffective environmental regulations as well as financial and human resource constraints are the major challenges facing developing countries in implementing environmental management practices [11]. 


\subsection{Prospects and enabling factors}

Several stakeholders responded that providing workshops and training programs to further understand the environmental and waste chapters would enhance the implementation of environmental management practices. One stakeholder said:

"There should be more communication with the Ministry of Environment through organized workshops to inform us about new laws because we sometimes find out about laws after there has been a catastrophe."

A study conducted in Uganda regarding the incentives and barriers to implementing national hospital standards emphasizes that external consultation and feedback on how standards should be dealt with is critical. Specific training is also required because staff should be professionally educated and competent [12]. Some of the participants believe that improving the environmental standards would be a good starting point. One of the common suggestions is to include a wastewater treatment clause within the Environmental Services Chapter.

Financial support to properly implement the environmental standards is crucial particularly for public hospitals due to the relatively less income that these hospitals have in return because they serve patients with low-income status. They described that some of the financial support could be through donations of items and equipment such as waste bins with foot pedals and reduced cost for audits. They added that the expenses of waste treatment should be shared by the Ministry of Environment. One of the participants belonging to a small private hospital suggested having waste treatment facilities per district.

Another enabling factor reported by the stakeholders is bank loans that may facilitate the process for hospitals that aim on complying with environmental standards. A study conducted by Smits et al. [13] recommended that accreditation agencies provide affordable loans for any type of facility renovation and improvement. Loans can also help hospitals to overcome resource deficiencies which prevent them from complying with standards [13]. For example, Japan compensates the financial burden that requires investment in equipment and technology through the support of government financial institutions. They are responsible for providing preferential taxation, low interest loans, depreciation payments and tax exemptions. This initiative is especially encouraging for hospitals facing difficult economic circumstances [14].

Establishing a rewarding system for hospitals that comply with the standards is an incentive that was reported by few stakeholders. They elaborated that this could be done by disseminating the names of good standing hospitals in the newspapers and the media. Recognizing their performance would motivate and encourage them to maintain and improve performance. A rewarding system may highly encourage the implementation of standards. One stakeholder said that penalizing hospitals for not implementing environmental standards should be correlated with availability of resources. Public reporting of accreditation results is also considered a rewarding incentive in the literature because it attracts more patients to these accredited hospitals. This approach is of high value especially to countries that are in their early stages of developing accreditation programs. However, it is important that publication of scoring schemes does not harm any of the hospitals, so it is important to know how to report results at the right level without causing any damage [13].

When asked whether receiving an environmental certificate, such as ISO 14001, in addition to accreditation is an incentive. Many of the stakeholders were not interested in receiving ISO 14001 as it is costly, not applicable and environmental management issues are not mandatory to be accredited by the Lebanese Accreditation Program. This may be 
attributed to the fact that environmental policies and regulations are not known to the stakeholders in addition to weak enforcement. Thus, for stakeholders to value and truly be interested in ISO 14001 there should first be more workshops and training sessions that introduce this initiative. A stakeholder in a public hospital in Mount Lebanon responded that:

"We are very interested in such a certificate but I can't decorate my house if I haven't built it. We first need documents, enlightenments, help, and financial support to implement ISO14001 and unfortunately we lack them all in Lebanon."

Most stakeholders prefer to invest in patient safety and the quality of service rather than environmental issues particularly that it is not a requirement for accreditation by the MoPH. Few stakeholders showed positive attitude towards receiving ISO 14001. One stakeholder explained that:

"Our priority is to implement the laws and regulations first. Later on, we would like to receive ISO 14001 because accreditation is not enough to control environmental issues."

\section{CONCLUSIONS AND RECOMMENDATIONS}

Trained environmental experts in hospitals are lacking which result in having other personnel responsible for health and safety, logistics, maintenance or engineering trying to meet the need. Concerned employees in the hospitals perceive the environmental standards as unclear, non-applicable, and non-enforceable. Moreover, the fact that implementing the environmental standards is not mandatory has influenced environmental management practices at hospitals and consequently environmental performance. The accreditation committee focuses and enforces the implementation of standards related to patient safety and quality improvement with the objective of improving the healthcare system. Undermining the environmental standards has conveyed false message regarding the significance of mitigating environmental impacts. Likewise, the method of random selection of the standards to be surveyed by the auditing body is not appropriate and undervalues environmental standards.

It is a well-established fact that healthcare facilities are adversely affecting the environment and consequently public health. In a few years, it is anticipated that environmental protection will become a legal obligation for hospitals. It is time for the healthcare sector to accept its environmental responsibilities to reduce the environmental impact of its operations. Developing sustainable environmental management practices requires a change in staff behavior which often occurs through ongoing staff education and training. Strengthening human and institutional capacity through a combination of training, technical assistance, and awareness programs is an essential initial step toward realizing effective environmental management practices. Financial support whether through developing public private partnerships or through the government is essential to facilitate the implementation of environmental management practices. The introduction of a national support system or advisory groups and the establishment of national institutes to guarantee loans would assist hospitals in implementing environmental standards and enable financing. Improving the environmental standards and enforcing them are equally important for responsible management. There is a need to review and update the environmental standards and integrate within a well-articulated policy framework which takes potential environmental impacts into consideration. 


\section{REFERENCES}

[1] Ng, G., Johnston, J., Leung, G. \& Cowling, B., Factors affecting implementation of accreditation programmes and the impact of the accreditation process on quality improvement in hospitals: a swot analysis. Hong Kong Medical Journal, 19(5), pp. 434-446, 2013.

[2] World Health Organization (WHO), Accreditation of hospitals and medical education institutions - challenges and future directions. EM/RC50/Tech.Disc.1, 2013.

[3] Eberle, J., Allain, L. \& Nersesian, P., Logistics of health care waste management: Information and approaches for developing country settings. Arlington, Va.: USAID, Deliver Project, Task Order 1, 2009.

[4] Mohamed, L.F., Abrahim, S.A. \& Al-Thukair, A.A., Hazardous healthcare waste management in the Kingdom of Bahrain. Waste Management, 29(8), pp. 2404-2409, 2009.

[5] Ammar, W., Wakim, R. \& Hajj, I., Accreditation of hospitals in Lebanon: a challenging experience. La Revue de Santé de la Méditerranée Orientale, 13(1), pp. 138-149, 2007.

[6] Mack, N., Woodsong, C., MacQueen, K., Guest, G. \& Namey, E., Qualitative research methods: A data collector's field guide, USA: Family Health International, 2011.

[7] Saleh, S., Sleinman, J., Dagher, D., Sbeit, H. \& Natafgi, N., Accreditation of hospitals in Lebanon: Is it a worthy investment? International Journal for Quality in Health Care, 5(3), pp. 284-290, 2013.

[8] El-Jardali, F., Ammar, W., Hemadeh, R., Jamal, D. \& Jaafar, M., Improving primary healthcare through accreditation: Baseline assessment of readiness and challenges in Lebanese context. International Journal of Health Planning and Management, 28(4), pp. 256-279, 2013.

[9] El-Jardali, F., Jamal, D., Dimassi, H., Ammar, W. \& Tchaghchaghian, V., The impact of hospital accreditation on quality of care: perception of Lebanese nurses. International Journal for Quality in Health Care, 20(5), 363-371, 2008.

[10] Novaes, H. \& Neuhauser, D., Hospital accreditation in Latin America. Revista Panamericana de Salud Pública, 7(6), pp. 425-430, 2000.

[11] Massoud, M.A., Fayad, R., Kamleh R. \& El-Fadel, M., Environmental Management System (ISO 14001) Certification in Developing Countries: Challenges and Implementation Strategies. Environmental Science \& Technology, 44(6), pp. 18841887, 2010.

[12] Bateganya, M., Hagopian, A., Tavrow, P., Luboga, S. \& Barnhart, S., Incentives and barriers to implementing national hospital standards in Uganda. International Journal for Quality in Health Care, 21(6), pp. 421-426, 2009.

[13] Smits, H., Supachutikul, A. \& Mate, K., Hospital accreditation: lessons from lowand middle-income countries. Globalization and Health, 10(65), 2014.

[14] Japan International Cooperation Agency (JICA). Japan's experiences in public health and medical systems, Online. https://www.jica.go.jp/jica-ri/IFIC_and_JBICIStudies/english/publications/reports/study/topical/health/index.html. $200 \overline{5}$. 